\title{
Uma análise sobre transmasculinidades presentes numa série da mídia televisiva
}

\author{
Un análisis sobre las transmasculinidades presentes en una serie de
} medios televisivos

An analysis of transmasculinities present in a television media series

\author{
Thais Geraldo Oliveira de Aguiar ${ }^{1}$ \\ Raquel Pereira Quadrado
}

\begin{abstract}
Resumo
Neste trabalho temos como objetivo analisar alguns significados sobre transmasculinidades presentes em dois episódios da série Liberdade de Gênero, exibida no canal de televisão brasileiro por assinatura GNT. Entendemos esta série como um potente artefato cultural para reflexão acerca das identidades trans, nela são apresentadas algumas histórias de pessoas que não se identificam com o gênero designado para elas ao nascerem, negando qualquer determinismo biológico. O preconceito, a exclusão social, a pressão religiosa e familiar que esses sujeitos vivenciam, no caso dos entrevistados, não venceram o desejo de ser quem sentiam ser. Nossos estudos têm como base os Estudos Culturais, na sua vertente pós-estruturalista, destacando o efeito das mídias na produção dos corpos e das sexualidades e também como produtora de saberes e conhecimentos, entendendo que os discursos veiculados pela mídia acionam efeitos de verdade e que essa proliferação de discursos vem atuando na produção dos sujeitos. A metodologia da pesquisa consiste na análise cultural, entendendo que esse tipo de análise é potente para pensar o quanto as pedagogias exercidas por estes artefatos são produtivas na constituição dos sujeitos e como vêm produzindo e reproduzindo significados acerca da transgeneridade, em específico sobre os homens trans.
\end{abstract}

Palavras chave: Transmasculinidades, Estudos Culturais, mídia televisiva.

\section{Resumen}

En este trabajo tenemos como objetivo analizar algunos significados sobre transmasculinidades presentes en dos episodios de la serie Libertad de Género, exhibida en el canal de televisión brasileño por firma GNT. Entendemos esta serie como un potente artefacto cultural para reflexionar acerca de las identidades trans, en ella se presentan algunas historias de personas que no se identifican con el género designado para ellas al nacer, negando cualquier determinismo biológico. El prejuicio, la exclusión social, la presión religiosa y familiar que esos sujetos vivencian, en el caso de los entrevistados, no vencieron el deseo de ser quienes se sentían ser. Nuestros estudios tienen como base los Estudios Culturales, en su vertiente post-estructuralista, destacando el efecto de los medios en la producción de los cuerpos y de las sexualidades y también como productora de saberes y conocimientos, entendiendo que los discursos vehiculados por los medios accionan efectos de verdad y que esta proliferación de discursos viene actuando en la producción de los sujetos. La metodología de la investigación consiste en el análisis cultural, entendiendo que ese tipo de análisis es potente para pensar cuánto las pedagogías ejercidas por estos artefactos son productivas en la constitución de los sujetos y cómo vienen produciendo y reproduciendo significados acerca de la transgeneridad, en específico sobre los hombres trans.

\footnotetext{
${ }^{1}$ Mestranda no Programa de Pós-Graduação em Educação em Ciências: Química da Vida e Saúde na Universidade Federal do Rio Grande (FURG), Rio Grande, Rio Grande do Sul, Brasil. thaisaguiar.furg@hotmail.com.

${ }^{2}$ Doutora em Educação em Ciências. Professora adjunta do Instituto de Educação da Universidade Federal do Rio Grande - FURG, orientadora no PPG em Educação em Ciências e no PPG em Educação. raquelquadrado@hotmail.com .
} 
Palabras clave: Transmasculinidades, Estudios Culturales, medios de comunicación televisiva.

\begin{abstract}
In this work we have the objective of analyzing some meanings about transmasculinities present in two episodes of the Freedom of Gender series, shown on the Brazilian GNT television subscription channel. We understand this series as a potent cultural artifact for reflection on trans identities, in which are presented some stories of people who do not identify with the gender assigned to them at birth, denying any biological determinism. Prejudice, social exclusion, religious and family pressure that these subjects experience, in the case of those interviewed, did not overcome the desire to be who they felt to be. Our studies are based on Cultural Studies, in its poststructuralist aspect, highlighting the effect of the media in the production of bodies and sexualities and also as a producer of knowledge and knowledge, understanding that the discourses conveyed by the media trigger effects of truth and that this proliferation of discourses has been acting in the production of the subjects. The research methodology consists in the cultural analysis, understanding that this type of analysis is potent to think how much the pedagogies exercised by these artifacts are productive in the constitution of the subjects and how they have been producing and reproducing meanings about transgenerality, specifically about trans men .
\end{abstract}

Key words: Transmasculinities, Cultural Studies, television media.

\title{
1. Contextualização
}

No cenário contemporâneo é notório que a discussão sobre diversidade de gênero vem avançando nas mídias, em torno disso, as identidades trans vêm ganhando visibilidade, como exemplo recente temos a série "Liberdade de Gênero", no canal GNT, que constitui o corpus de análise desse trabalho. A série mostra em 10 episódios como se organizam as vidas de quem assume a realidade de ter um gênero diferente daquele esperado a partir do seu sexo biológico.

Além disso, a novela das 21h "A Força do Querer", veiculada no horário nobre da emissora Rede Globo em 2017, trouxe duas personagens envolvidas com a questão trans. Elis Miranda, que se autodeclarava travesti e Ivana que não reconhecia seu corpo feminino e no decorrer da novela passou a se entender como um homem trans, identificando-se como Ivan. A história de Ivan repercutiu tanto que ele se tornou um dos personagens principais da trama.

Em torno dessa visibilidade das transmasculinidades, buscamos analisar os dois episódios da série Liberdade de Gênero que apresentam a história de homens trans. De acordo com Ávila (2014), trans-homens são indivíduos que foram identificados como meninas no nascimento, mas se identificam com o gênero masculino.

Trazemos essa pesquisa a partir do campo teórico dos Estudos Culturais, na sua vertente pós-estruturalista de análise, destacando o efeito das mídias na produção dos corpos e das sexualidades e também como produtora de saberes e conhecimentos. Nesse sentindo, entendemos a série Liberdade de Gênero como um potente artefato cultural para a reflexão acerca das identidades trans e das sexualidades, uma vez que contém pedagogias culturais que ensinam significados sobre esses sujeitos. 
Conforme destacam Soares e Meyer,

$\mathrm{O}$ conceito de pedagogias culturais remete, exatamente, para o reconhecimento e problematização da importância educacional e cultural da imagem, das novas tecnologias da informação, enfim, da relação entre educação e cultura da mídia nos processos de organização das relações sociais e na produção das identidades. (2003, p.139)

\section{Objetivo}

Analisar os significados acerca das transmasculinidades em dois episódios da primeira temporada da série Liberdade de Gênero que estreou em 19 de outubro de 2016, a mesma lançou uma segunda temporada no dia 02 de outubro de 2017.

\section{Metodologia}

A metodologia da pesquisa consistiu em analisar dois episódios da primeira temporada da série Liberdade de Gênero - o terceiro episódio e o sétimo episódio - dirigida e produzida pelo cineasta João Jardim, veiculada pela rede de TV fechada GNT e também na internet, disponível na GNT Play ${ }^{3}$, com aproximadamente vinte e dois minutos de duração cada episódio. No presente trabalho buscamos analisar as falas dos homens trans entrevistados problematizando as transmasculinidades, a partir de ferramentas da análise cultural.

De acordo com Rocha (2011), o que a análise cultural indica é o fato de que a televisão corresponde a um dos principais domínios na contemporaneidade através dos quais a cultura circula e é produzida. Dessa forma, entendemos que os programas televisivos, como a série Liberdade de Gênero, constituem potentes artefatos culturais a serem analisados, visto que possuem uma dimensão cultural, produzindo significados.

As análises culturais, de acordo com Wortmann (2007), visibilizam relações e aspectos que geralmente não são considerados em análises tradicionais, tais como aquilo que acontece no cotidiano das pessoas e que produz efeitos em suas vidas. Trata-se de analisar práticas culturais considerando-as produzidas e imersas em relações de poder, constituindo formas interessadas de lidar com tais práticas.

\section{Resultados}

Nessa seção apresentamos algumas análises que temos empreendido. O terceiro episódio da série Liberdade de Gênero foi ao ar no dia 02 de novembro de 2016, sendo o primeiro a trazer um homem trans, contando a história de Erick (Figura 1), que nasceu num

\footnotetext{
${ }^{3}$ Disponível em: https://globosatplay.globo.com/gnt/liberdade-de-genero/ acesso em: 10/10/2017.
} 
corpo feminino, mas sempre se entendeu como um menino. Aos 19 anos ele descobriu que era possível fazer a transição de gênero e iniciou o seu processo para se tornar um homem trans.

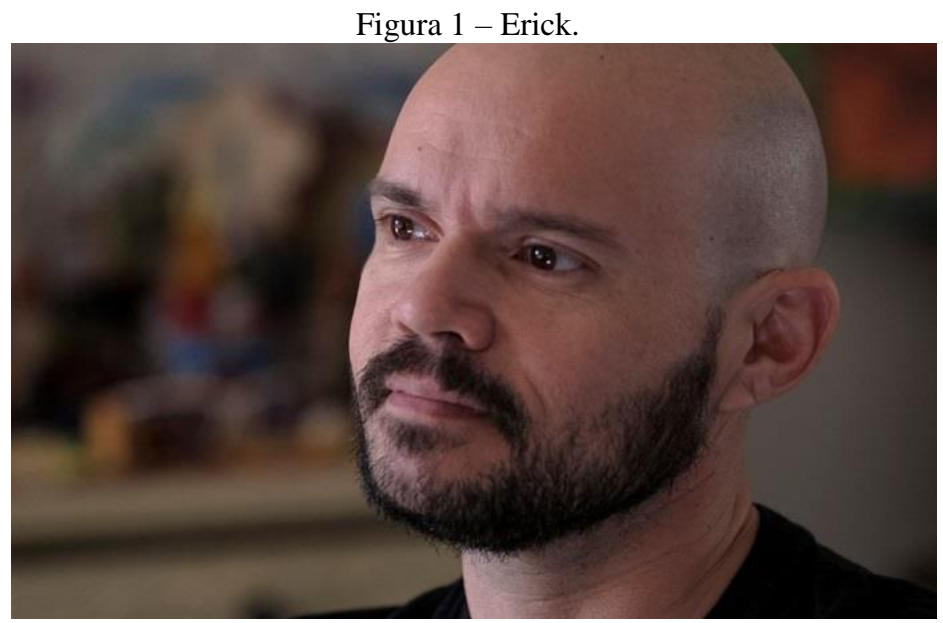

Fonte: Imagem retirada da série Liberdade de Gênero.

Exibido em 30 de novembro de 2016, o sétimo episódio da série conta a história do segundo homem trans entrevistado. Sillvio Lúcio (Figura 2) mora no interior do Ceará e se identifica como homem trans há 12 anos. Ele é casado há 16 anos com Widina, sua esposa acompanhou e apoiou a transição de gênero.

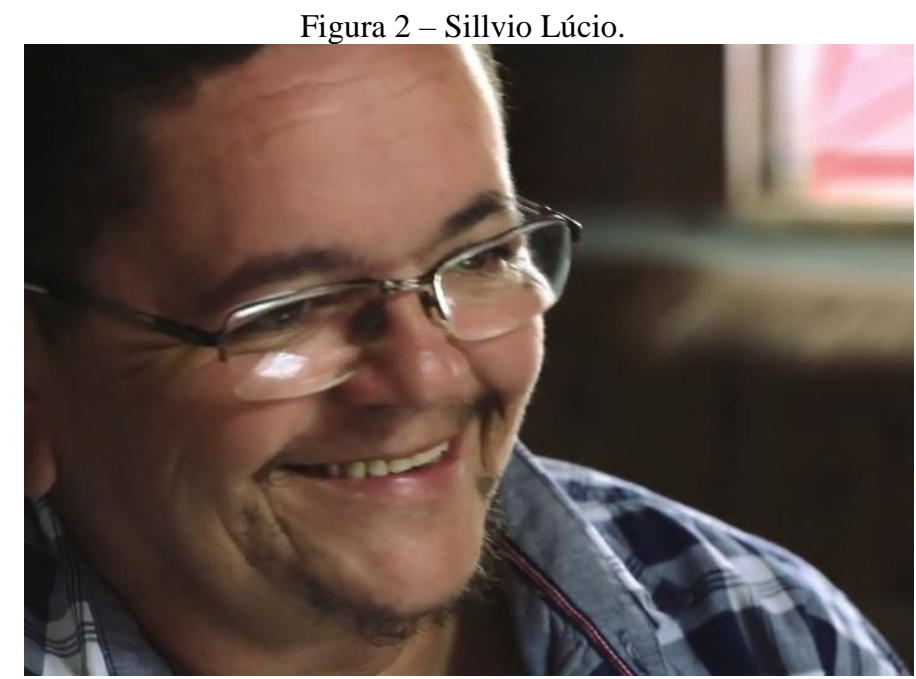

Fonte: Imagem retirada da série Liberdade de Gênero.

Erick é o único homem trans na série que fez a cirurgia de mastectomia, além disso, faz tratamento hormonal contínuo com testosterona. Ele conta que percebeu que estava fadado a viver como menina quando veio à primeira menstruação, que se trancou no banheiro e pensou em se matar. Ele diz: Foi a minha sentença de morte! Todas as minhas esperanças 
acabaram ali e a minha mãe batendo na porta e dizendo: ai, que legal, você virou mocinha! E eu querendo cortar os pulsos. Eu tinha a convicção de que nasci errado! Mas, que teria que viver no corpo errado, até eu aguentar. Se eu não descobrisse que eu era transexual, eu teria me matado.

A história de Sillvio Lúcio se difere um pouco da de Erick, porque Sillvio não se submeteu à cirurgia de mastectomia por medo, já que ele conta: Nós temos vários amigos que fizeram a mastectomia e não foram bem sucedidos, ficaram com seus corpos danificados $e$ feios, alguns perderam o movimento do braço. Por conta disso, Sillvio utiliza outras estratégias para que os seios, que são marcadores femininos muito fortes, não sejam percebidos como faixas e cintas que diminuem o volume na região do peito.

Ambos relatam sobre as situações de preconceito e constrangimento que vivenciaram e/ou vivenciam em relação ao corpo e à aparência física não ser condizente com o nome e com o gênero do documento de identidade, por exemplo. Erick, em 2008, ganhou na justiça o direito de realizar a mudança de nome nos documentos oficiais. Sillvio diz que: se existem duas vagas de emprego entre contratar o Sillvio Lúcio e contratar uma pessoa cis heterossexual, a pessoa cis heterossexual vai ser contratada. É o chamado preconceito silencioso. Eu escuto muito as pessoas dizerem: Sillvio, tu és muito inteligente, se tu não fosses transexual tu eras secretário ou tinha sido eleito vereador.

Lanz traz essa questão quando coloca que a pessoa cujo comportamento se desvia dos padrões oficiais de conduta de gênero:

\begin{abstract}
De maneira sutil ou ostensiva, ela passa a ser sistematicamente excluída do convívio com pessoas "normais", ou seja, as pessoas "generadas" (leia-se: obedientes, perfeitamente enquadradas e submissas ao dispositivo de gênero). Dependendo de como a sociedade enxergue a "natureza da sua transgressão", pode passar a ser tratada como pervertida e depravada ou como 'doente mental'. Para "transgressores" de gênero, tudo que a sociedade reserva é o estigma, a marginalização, a exclusão, o 'limbo social’ (2008, p.65).
\end{abstract}

Uma questão presente em suas falas, que assombrava as infâncias, era a pressão religiosa, pois se eles não brincassem de boneca, por exemplo, uma brincadeira considerada típica do gênero feminino, diziam que eles iriam para o inferno, por estar pecando. Sillvio comenta que até brincava de boneca com meninas da idade dele, mas, ele sendo o papai da boneca na brincadeira. A questão da religiosidade vem muito forte, principalmente na história de Sillvio Lúcio, que tinha uma família cristã evangélica fervorosa.

Castro e Ferrari (2017) trazem apontamentos sobre o direcionamento moral dos pensamentos, a partir de certas 'leituras’ da bíblia cristã. 
Tal direcionamento se organiza partir do pressuposto heteronormativo e cissexista, baseado na ideia de que os sujeitos que vivem sexualidades não-heterossexuais e gêneros não binários estariam em desacordo com o propósito sagrado e o plano divino, ameaçando crenças e valores que sustentam as relações sociais. (2017, p.78)

Outro fato marcante nos dois episódios analisados é o desconforto com as condutas, com o comportamento e até com as brincadeiras do gênero estabelecido, que despertam muito cedo, desde a infância. Por exemplo, Erick conta que na escola chegava a mudar as placas de identificação de meninas e meninos para poder entrar no banheiro de meninos. Enquanto Sillvio negociava com seus irmãos para poder andar de bicicleta e usar calças compridas, já que as meninas na época só podiam usar saias em virtude da religião que a família dele praticava. Ele justifica dizendo: eu queria brincar no pátio na bicicleta deles, porque eu me sentia numa moto ou num cavalo aquela questão do homem, né? Da independência e da fortaleza masculina.

Isso se justifica porque quando um bebê nasce junto com ele nasce um conjunto de expectativas sociais que são estabelecidas a partir de seu sexo biológico, isto é, desde pequenos (as) somos ensinados (as) que o nosso sexo biológico determina nosso gênero e que dependendo do gênero determinado é preciso cumprir com determinados papéis, condutas e comportamentos que são esperados dentro da nossa sociedade.

Bento aponta que:

O gênero só existe na prática, na experiência, e sua realização se dá mediante reiterações cujos conteúdos são interpretações sobre o masculino e o feminino em um jogo, muitas vezes contraditório e escorregadio, estabelecido com as normas de gênero. $\mathrm{O}$ ato de pôr uma roupa, escolher uma cor, acessórios, o corte de cabelo, a forma de andar, enfim, a estética e a estilística corporal, são atos que fazem o gênero, que visibilizam e estabilizam os corpos na ordem dicotomizada dos gêneros. Tanto os/as homens/mulheres biológicas se fazem na repetição de atos que se supõe sejam os mais naturais. (2014, p. 60)

Podemos aqui pensar, naquilo que Butler chamou de performatividade de gênero. "O gênero é performativo porque é resultante de um regime que regula as diferenças de gênero. Neste regime os gêneros se dividem e se hierarquizam de forma coercitiva" (2002, p. 64).

Ambos colocam que desde a adolescência suas paixões sempre foram por mulheres e que inicialmente questionavam sua sexualidade, entendendo-se como lésbicas, porém, com o passar do tempo souberam diferenciar que os problemas não perpassavam a sexualidade, mas, sim, as identidades de gênero, em como eles se reconheciam. Erick diz que: a adolescência foi muito difícil, porque cain no meu colo que eu era uma lésbica e que eu teria que viver nesse corpo, que eu tinha nascido errado. 
O conceito de transgeneridade é muito recente, no Brasil, e por muito tempo as pessoas trans foram reconhecidas como homossexuais. Diante disso, socialmente costuma-se fazer um entrelaçamento entre as identidades de gênero e as identidades sexuais, embora, não seja a mesma coisa.

Para Guacira Louro:

enquanto a identidade de gênero liga-se à identificação histórica e social dos sujeitos, que se reconhecem como femininos ou masculinos, a identidade sexual está relacionada diretamente à maneira com que os indivíduos experenciam seus desejos corporais, das mais diversas formas: sozinhos/as, com parceiros do mesmo sexo ou não, etc. (1997. p. 33)

\section{Conclusões}

Escolhemos a série Liberdade de Gênero para análise, por entendermos que os programas televisivos contêm pedagogias que veiculam significados que nos ensinam modos de ser e de entender sobre as identidades trans. Além disso, ao serem apresentados na mídia televisiva, tais significados assumem efeitos de verdade, pois ao serem enunciados em um canal de TV vinculado a uma emissora de grande repercussão no país, "isso se põe a funcionar na cabeça de milhares de pessoas como verdade, unicamente porque foi pronunciado daquela maneira, naquele tom, por aquela pessoa, naquela hora”. (FOUCAULT, 2003, p. 233)

A série busca mostrar histórias onde os transgêneros se inserem de forma feliz e bem sucedida dentro da sociedade. Enquanto a maioria dos programas foca em mostrar a marginalização desses sujeitos, a questão do caráter patológico que essa temática envolve ou a excentricidade que essa minoria desperta, neste programa vemos algumas rupturas com o discurso recorrente, geralmente carregado de preconceito.

Além disso, a trilha sonora com que a série inicia seus episódios já aparenta ser um convite ao telespectador a quebrar com certos paradigmas sobre gêneros e sexualidades, com a música Zero, do compositor e um dos entrevistados da série Liniker, o refrão é repetido por várias vezes "deixa eu bagunçar você, deixa eu bagunçar você" .

O preconceito, a exclusão social, a pressão religiosa e familiar que esses sujeitos vivenciam, no caso dos entrevistados, não venceram o desejo de ser quem sentiam ser. $\mathrm{Na}$ série são apontados alguns significados sobre as identidades trans, importantes para que possamos refletir acerca dessa temática, ainda pouco problematizada. Tais como: o gênero como uma construção e as múltiplas identidades que nos constituem. 
Para Guacira Louro "ao assumir que os gêneros são produzidos cultural e historicamente, parece ser imprescindível admitir que os gêneros se fazem, sempre, com as marcas particulares de uma cultura, com os recursos e signos específicos de um tempo e de um lugar”. (2003. p. 06). Além disso, os gêneros são produzidos pela linguagem, ou seja, não existe gênero antes da linguagem, de modo que "se quiséssemos, poderíamos dizer: não é que uma identidade 'faça' o discurso ou a linguagem, mas é precisamente o contrário - a linguagem e o discurso é que 'fazem' o gênero”. (SALIH, 2012, p.91)

Fisher (2013, p.146) coloca que "estamos sempre diante de uma concepção de discurso como luta: luta pela imposição de sentidos, pela interpelação de sujeitos, pela conquista de voz"... Em torno disso refletimos o quanto isso se relaciona com os discursos que neste artigo analisamos discursos permeados de lutas e batalhas de pessoas que enfrentam tantas barreiras para poder ser quem são.

\section{Referências}

ÁVILA, S. Transmasculinidades: a emergência de novas identidades políticas e sociais. 1. Ed. Rio de Janeiro: Editora Multifoco, 2014.

BENTO, Berenice. O que pode uma teoria? Estudos Transviados e a Despatologização das Identidades Trans. Florestan, n. 2, p. 46, 2014.

BUTLER, Judith. Críticamente subversiva. In: JIMÉNEZ, Rafael M. Mérida. Sexualidades transgresoras. Una antología de estudios queer. Barcelona: Icária editorial, 2002, p. 55 a 81.

CASTRO, Roney Polato de. FERRARI Anderson. Educação, experiências religiosa, gêneros e sexualidades: algumas problematizações. In: RIBEIRO, Paula Costa. MAGALHÃES, Joanalira Corpes (Org). Debates contemporâneos sobre Educação para sexualidade. Rio Grande: Editora da FURG. 2017.

FISHER, Rosa. Maria. Bueno. Foucault. In.: OLIVEIRA, Luciano Amaral (Org.). Estudos do discurso: perspectivas teóricas. São Paulo: Parábola Editorial, 2013. p. 123-151.

FOUCAULT, Michel. Poder-saber. In: Ditos \& Escritos IV. Estratégia, poder-saber. Rio de Janeiro: Forense Universitária, 2003. p. 223-240.

LANZ, Leticia. Uma Introdução Longa Porém Necessária. 2008. Disponível em <http://www.leticialanz.org/uma-introducao-longa-porem-necessaria>. Acesso em: 18 set 2017.

LOURO, Guacira. Gênero, sexualidade e educação. Petrópolis: Vozes, 1997. . Corpos que escapam. Labrys estudos feministas. Florianópolis, n. 4, 2003. 
Portal da série Liberdade de Gênero. Disponível em:

<https://globosatplay.globo.com/gnt/liberdade-de-genero/>. Acesso em: 10 out 2017.

ROCHA, S. M. Os estudos culturais e a análise cultural da televisão: Considerações teóricometodológicas. Rev. Interamericana de Comunicação Midiática, Santa Maria, v.10, n.19, sem. 2011.

SALIH, Sara. Judith Butler e a Teoria Queer. Belo Horizonte: Autêntica. 2012.

SOARES, Rosêngela; MEYER, Dagmar. O que se pode aprender com a "MTV de papel" sobre juventude e sexualidade contemporâneas?. Revista Brasileira de Educação, Porto Alegre, n. 23, p. 136-148, maio/jun/jul/ago. 2003.

WORTMANN, Maria Lúcia. Análises Culturais. In: COSTA, Marisa Vorraber (Org.). Caminhos Investigativos II: outros modos de pensar e fazer pesquisa em educação. 2 ed. Rio de Janeiro: Lamparina, 2007. p. 71-90 